\title{
Tissue Adhesion
}

National Cancer Institute

\section{Source}

National Cancer Institute. Tissue Adhesion. NCI Thesaurus. Code C54685.

A fibrous band of tissue that connects normally separate body regions. 